\title{
Pancreatic Duct Obstruction in the Pig: Electron Microscopy of Chronic Pancreatitis
}

\author{
By Timo Rahko, Hannu Saloniemi and Timo V. Kalima
}

\begin{abstract}
Rahko, T., H. Saloniemi and T. V. Kalima: Pancreatic duct obstruction in the pig: Electron microscopy of chronic pancreatitis. Acta vet. scand. 1988, 29, 255-258. Ultrastructural alterations of pancreatic tissues in growing pigs caused by surgical ligation of the main pancreatic duct are described. Five animals aged 6 to 7 weeks were operated on and necropsied 2, 6 or 8 weeks later. In addition, 3 pigs that were sham-operated served as controls. Obstruction of the ducts caused progressive luminal dilatations and rupture of intercellular connections of the epithelium followed by destruction and atrophy of acinar parenchyma and proliferations of immature ductular epithelial cells free from zymogen granules.
\end{abstract}

pancreatic duct ligation; exocrine pancreatic insufficiency; experimental chronic pancreatitis; porcine pancreas diseases.

\section{Introduction}

Chronic pancreatitis in man is a progressive disease usually afflicting middleaged persons and leading to complete exocrine insufficiency (Andersson 1979, Longnecker 1982). Of animals, dogs and cats suffer from pancreatic insufficiency much more frequently than horses, cows and pigs. Pigs may develope spontaneous pancreatitis due to obstruction of the pancreatic ducts by ascarid parasites (Andersson 1979). Exocrine obstruction in man is also a significant etiological factor for the pathogenesis of pancreatitis (Longnecker 1982, Klöppel et al. 1986). Pancreatic duct ligation in small laboratory animals and the dog is usually applied in experimental studies of chronic pancreatic diseases (Rahko et al. 1986, Catala et al. 1987). In pigs, only acute pancreatic lesions are closely described by electron microscopy in previous reports (Pang et al. 1986).
The development of pancreatic enzyme preparations is based on animal experiments. An omnivorous animal model with exocrine pancreatic insufficiency was created by the authors via ligation of ductus pancreaticus in growing pigs (Rahko et al. 1985, Rahko et al. 1987). Light microscopy revealed chronic pancreatitis with ectasia of the ducts and atrophy of acini followed by duct cell proliferations (Rahko et al. 1987). This report deals with ultrastructural alterations of pancreatic tissues caused by the ligation during the chronic phase.

\section{Materials and methods}

The experimental and control animals were Yorkshire pigs (females and castrated males) aged from 6 to 7 weeks. During the operation performed in halothane-anesthetized animals the serosal connection between the right branch of the pancreas and duodenum 
was cut and the pancreatic duct was ligated near the duodenum in the experimental pigs (5 animals). Controls (3 animals) were sham-operated, being subjected only to a laparatomy. All pigs were fed a commercial pig food ad libitum. The pigs were sacrificed and necropsied 2 weeks ( 2 experimental animals), and 6-8 weeks ( 3 control animals and 3 experimental animals) after the ligation.

For electron microscopy the tissue blocks were fixed for 2 to $6 \mathrm{~h}$ in $2.5 \%$ glutaraldehyde in $0.1 \mathrm{~mol} / 1$ phosphate buffer, washed in buffered $10 \%$ sucrose, postfixed in $1 \%$ osmium tetroxide in the same buffer for $2 \mathrm{~h}$, then dehydrated and embedded in epoxy resin. Thin sections were mounted on copper grids, stained with uranyl acetate and lead citrate and examined in a JEOL JEM $100 \mathrm{~S}$ transmission electron microscope.

\section{Results}

Electron microscopy of the pancreas in the controls showed an exocrinic tissue consisting of acinocytes rich in zymogen granules and granular endoplasmic reticulum, and of duct epithelium characterized by the paucity of cytoplasmic organelles. Other tissue elements including endocrinic islet cells and blood capillaries also presented normal ultrastructural features.

Two weeks after the ligation (Figs. 1-5), electron microscopy of the experimental animals revealed dilatations of ducts with fine granular intraluminal contents spreading into the intracellular spaces through ruptured cellular junctions. In these areas the acinocytes appeared to be degenerating, showing wide dilatations of endoplasmic membranes free from ribosomes and general vacuolisation of the cytoplasm. In sections distant from the ducts, on the other hand, fairly normal features were noted in the perivascular endocrinic and the peripheral acinar cell. However in the partly degene- rating areas, ectasia of intercellular spaces between acinocytes was obvious while cytoplasmic organelles such as zymogen granules and the Golgi complex appeared rather well preserved.

Different types of endocrine cells were identified in islet parenchyma. Most numerous were the B-cells. Beta granules showed electron dense and usually barshaped cores surrounded by an electron-lucent space and a smooth-surfaced membrane. A-cells presented granules with rounded electron-dense cores closely limited by a capsule. The cells displayed rounded or elongated profiles of mitochondria, the cristae of which were partly fragmented due to degenerative processes.

Electron micoscopy of tissue specimens from pigs killed from 6-8 weeks after the ligation (Figs. 6-8) revealed an almost complete disappearance of acinar parenchyma. Atrophy of acinocytes was followed by proliferations of immature epithelial cells free from zymogen granules. The cells proliferated diffusely or formed duct-like structures, among which separate, mature-looking endocrine cells were identified. The cytoplasm of the cells was scanty; free from zymogen granules and poor in organelles. Many of the cells presented degenerative features including vacuolisation of nuclei and mitochondriae and intracytoplasmic presipitates. In diffuse proliferations wide intercellular spaces were present, while in the ducts the adjoining intercellular contacts were interdigitated showing frequent desmosomes. The lumina of the ducts appeared free from electron-dense accumulations. They were lined by uneven cytomembranes with a few and irregular villous processes.

\section{Discussion}

In a previous light microscopical study the authors showed that pancreatic duct ob- 
Timo Rahko, Hannu Saloniemi and Timo V. Kalima: Pancreatic duct obstruction in the pig: Electron microscopy of chronic pancreatitis.

Figure 1. Pronounced degeneration of acinocytes around a pancreatic duct with dilatations of intercellular spaces (arrows). experimental animal 2 weeks postligation. $\times 2.000$.

Figure 2. Slight degeneration of acinic parenchyma adjoining interstitial tissues. $\mathrm{N}=$ nervous tissue in interstitium. Experimental animal 2 weeks postligation. $\times 2.000$.

Figure 3. Detail of partly degenerated acinocyte with vacuolated endoplasmic reticulum. $G=$ Golgi complex. $Z=$ zymogen granules. Experimental animal 2 weeks postligation. $\times 10.000$.

Figure 4. A survey electron micrograph of rather well preserved perivascular endocrine cells. $A=$ granules of A-cells. B = granules of B-cells. Experimental animal 2 weeks postligation $\times 2.000$.

Figure 5. Detail of A-cell with glucagon-containing granules. $A=$ nucleus of A-cell. Experimental animal 2 weeks postligation. $\times 5.000$.

Figure 6. Acinic parenchyma is replaced by proliferating immature duct epithelial cells poor in cytoplasmic organelles. Experimental animal 8 weeks postligation. $\times 2.000$.

Figure 7. Proliferating duct epithelial cells display short microvilli on the luminal surface. Experimental animal 8 weeks postligation. $\times 4.000$.

Figure 8. Proliferating duct epithelial cells are connected with tight desmosomes. The cytoplasmic membranes between the cells show interdigitations. Experimental animal 8 weeks postligation. $\times 15.000$. 

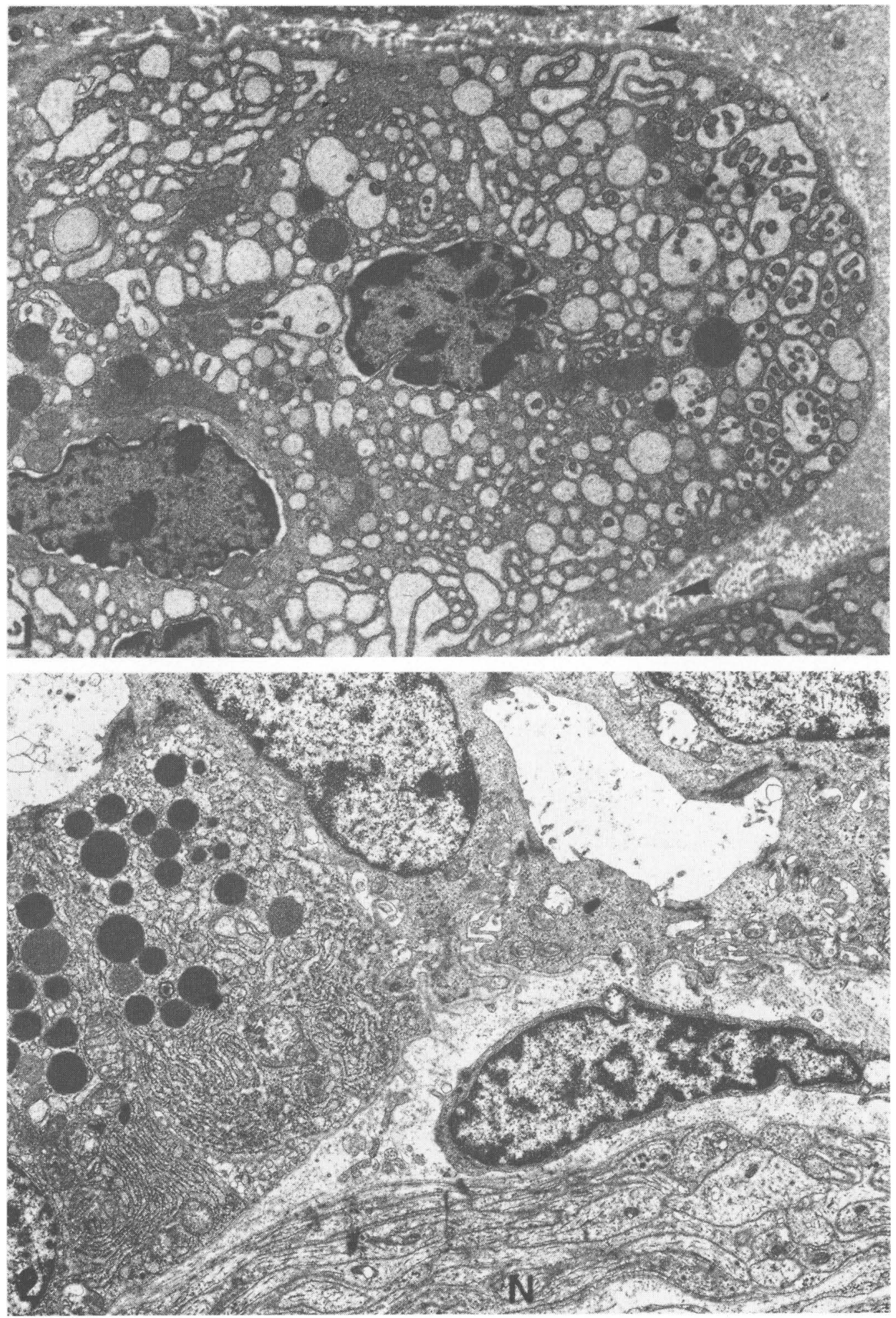


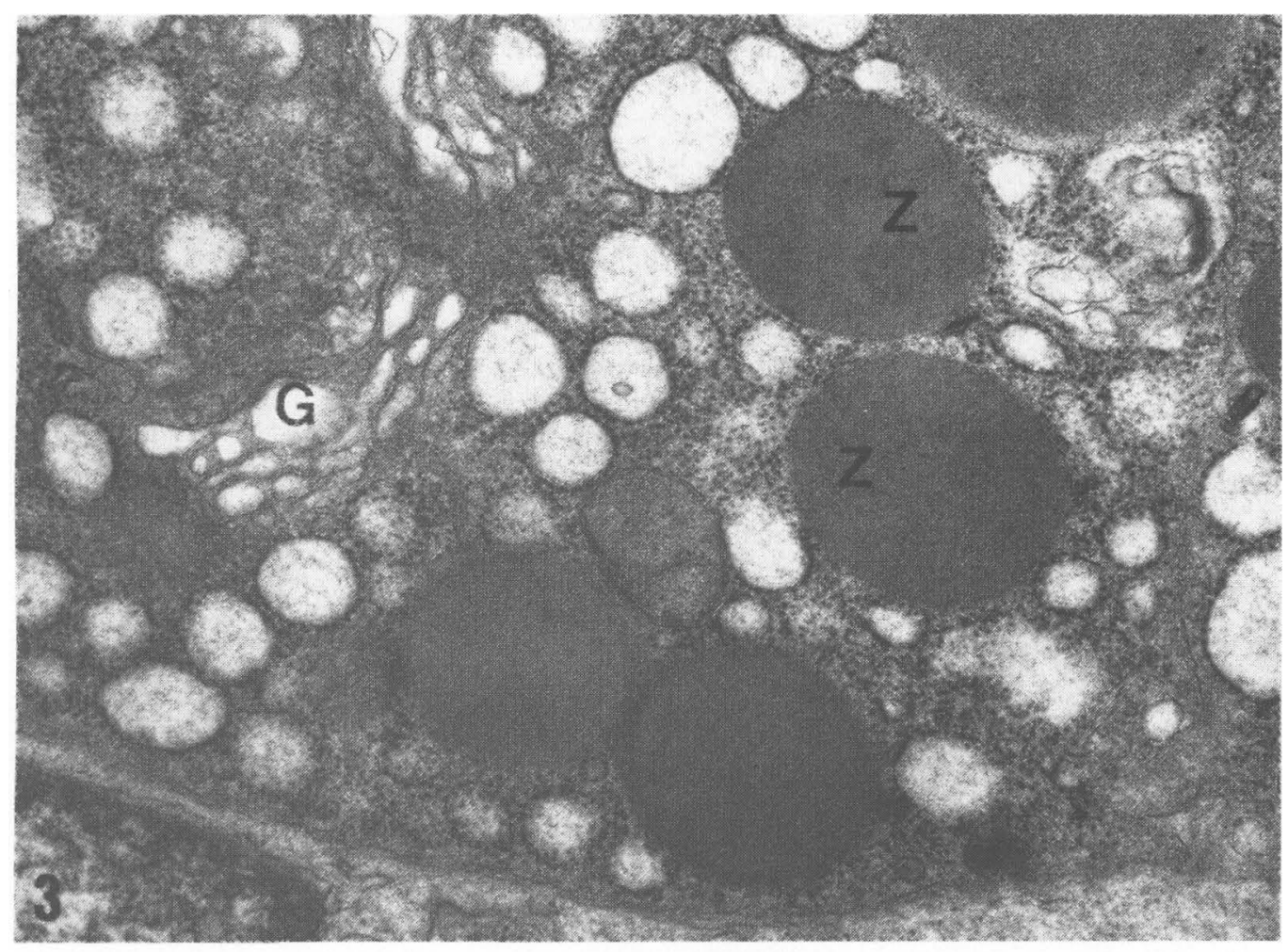

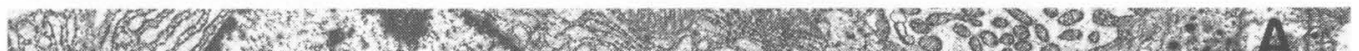

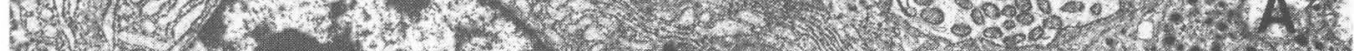

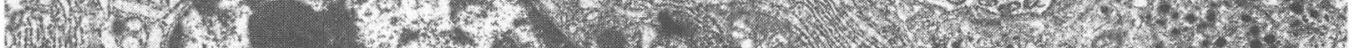

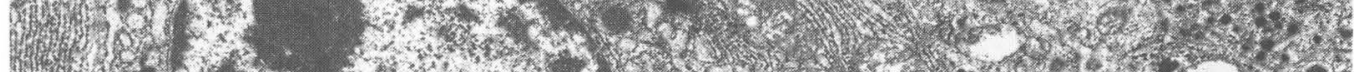

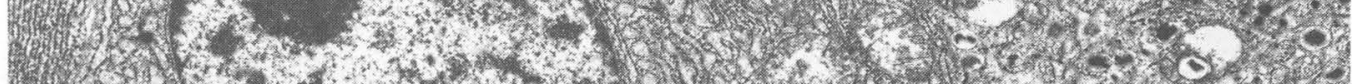

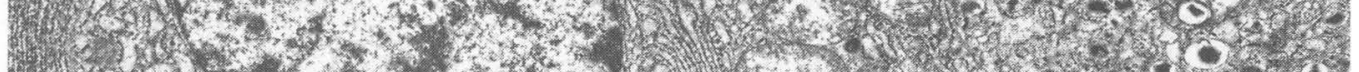

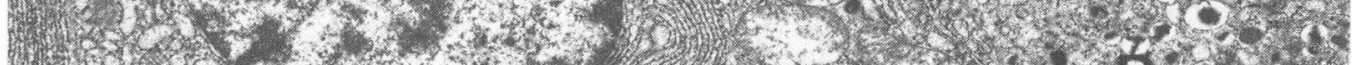

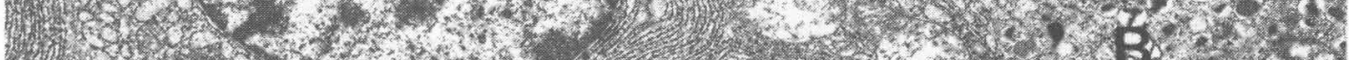

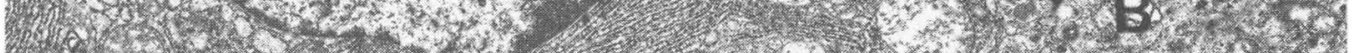

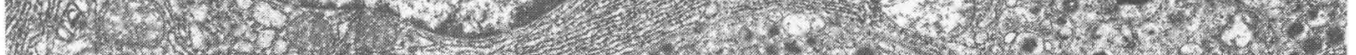

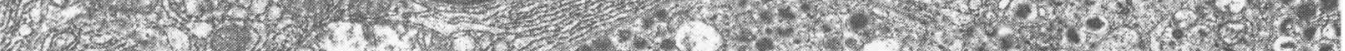

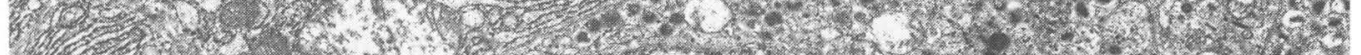

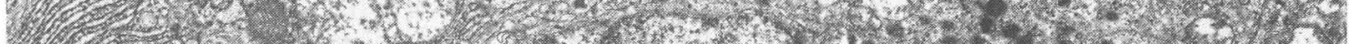

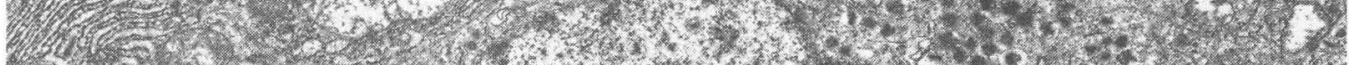

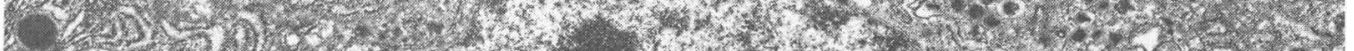

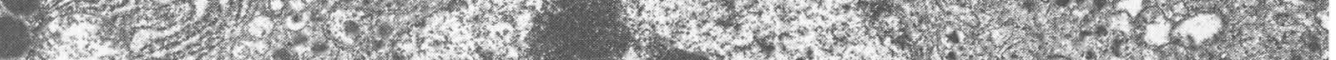

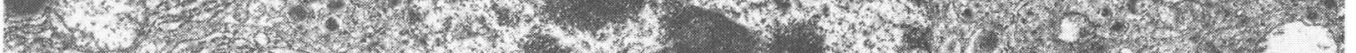

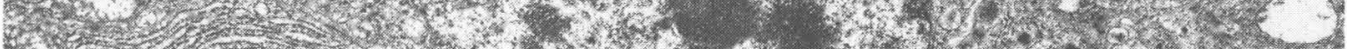

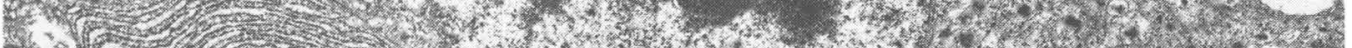

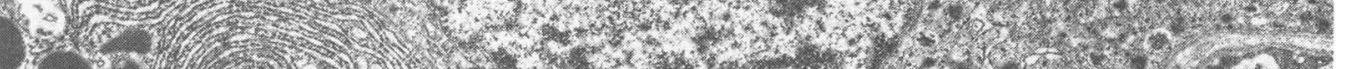

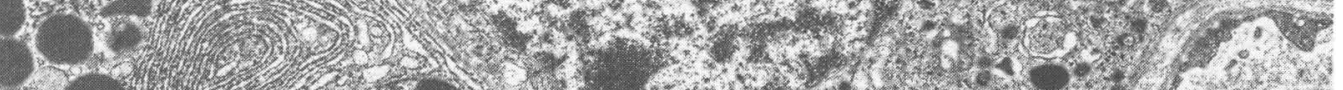

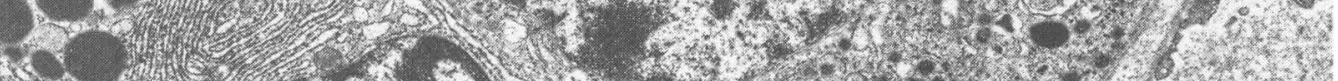

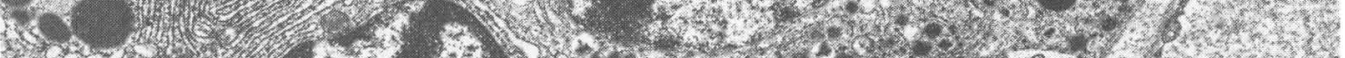

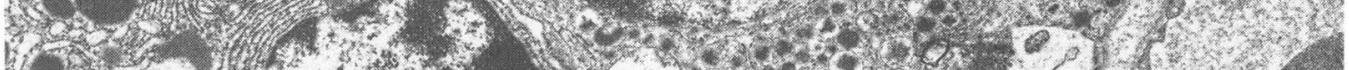

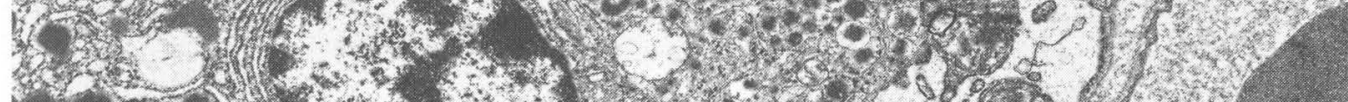

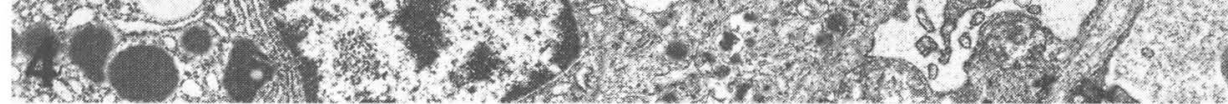



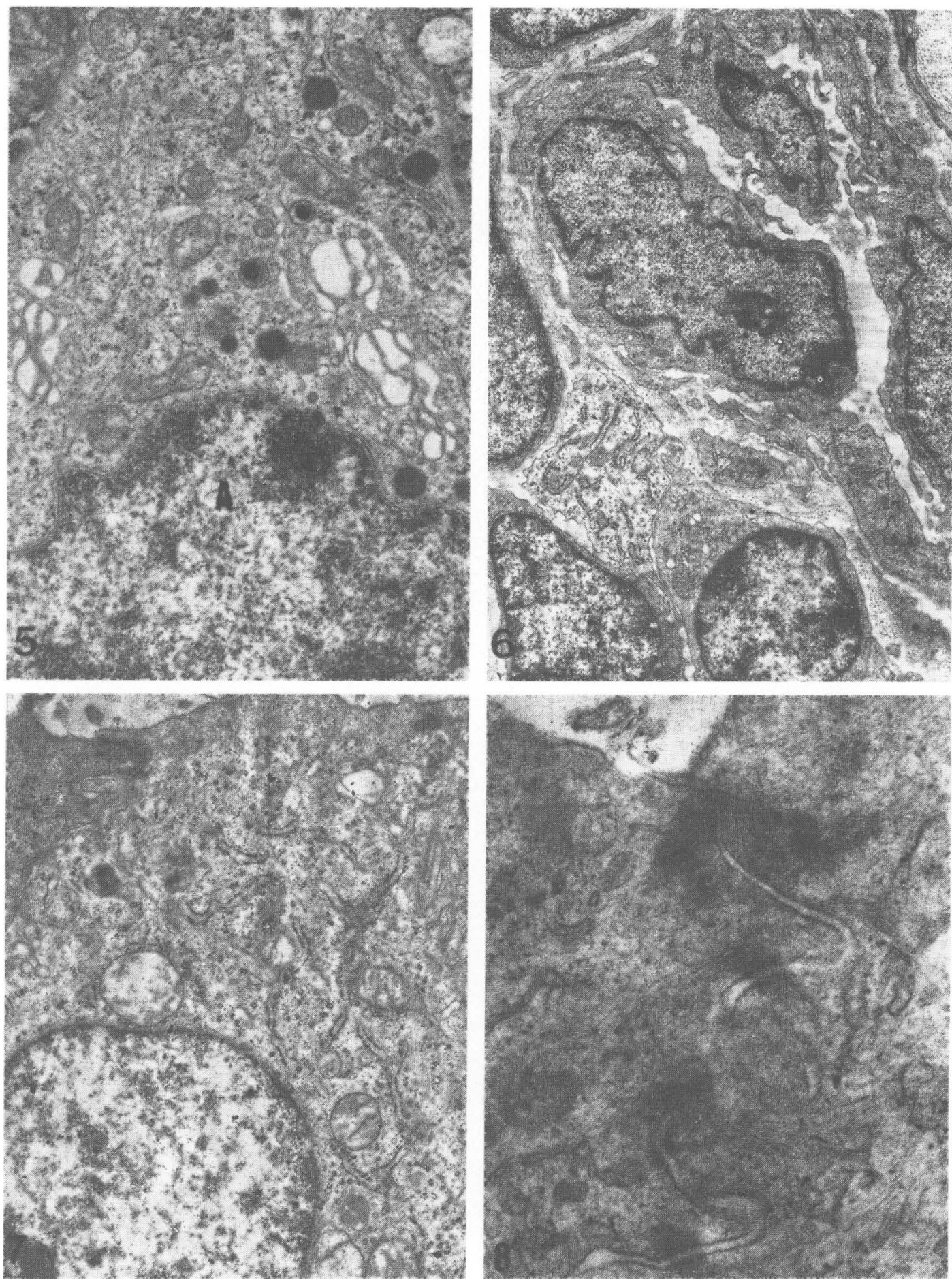
struction in the pig produces chronic pancreatitis with dissappearance of acini followed by ductular cell proliferations around ectatic ducts (Rahko et al. 1987). The present investigation on chronic phase of the disease confirmed and extended our previous results. The proliferations are composed of immature epithelial cells free from zymogen granules while the endocrine islets remain alive.

Experiments on small laboratory animals have concentrated on elucidating the pathogenesis of the acute phase in pancreatic duct obstruction (Zelander et al. 1964, Walters et al. 1969, Boquist \& Edström 1970, Churg \& Richter 1971, Catala et al. 1987). Studies have shown that early phase acinar cell death is caused by other mechanisms than merely pressure atrophy. Synthesis of zymogen granules rapidly ceases after the duct ligation, due to osmotic injury and cellular swelling (Zeligs et al. 1975). The number of zymogen granules per acinar cell gradually decreases, followed by death of the cells by a lysosomally-mediated mechanism (Zeligs et al. 1975). Acinar cell death is very rapid phenomenon in small laboratory animals. (Zelander et al. 1964, Walters et al. 1969, Boquist \& Edström 1970, Churg \& Richter 1971, Schiller et al. 1974). However, according to present study it takes longer than 2 weeks in the pig.

Luminal dilatation is an unavoidable consequence of the experimental ligation of ductus pancreaticus in the pig, as also in small laboratory animals (Zelander et al. 1964, Boquist \& Edström 1970). Obstruction of the flow of pancreatic secretions resulted in ectatic ducts filled with a clear watery fluid in the present material. Previously the present authors have shown that the fluid is free from protease activity (Rahko et al. 1986). Correspondingly, in the ultrastructure of the cells present $6-8$ weeks after the ligation, no zymogen granules could be shown. The enzyme-free contents of the ducts are, according to previous observations, bicarbonaterich secretions from the duct epithelium (Boquist \& Edström 1970).

The present study confirmed earlier results in that also in the pig the postligative degenerative alterations affect excocrinic tissues, while endocrine islets better tolerate the progressive luminal dilatations. It is obvious that the islets situated far from the ectatic ducts are protected against the destructive effect of refluxing pancreatic secretions. The acinar cells, on the contary, are in close contact with pancreatic enzymes, due to ruptures of junctional complexes. It is also obvious that acinar cell death is part of a remodelling process (Zeligs et al. 1975). Atrophy removes nonfunctioning acini and prevents further synthesis of damaging pancreatic enzymes, and thus protects against lethal forms of pancreatitis (Zeligs et al. 1975).

\section{Acknowledgements}

Electron microscopial studies were performed in the Laboratory of Electron Microscopy, College of Veterinary Medicine, Helsinki.

\section{References}

Andersson $N V$ : Chronic (relapsing) pancreatitis. In: Spontaneous Animal Models of Human Disease, Ed. Andrew EJ, Ward BC, Altman NH. Vol. I, Academic Press, New York 1979, p. 34-36.

Boquist L, Edström C: Ultrastructure of pancreatic acinar and islet parenchyma in rats at various intervals after duct ligation. Virchows Arch. Abt. A Path. Anat. 1970, 1970, 349, 69-70.

Catala J, Bonnafous R, Dutrillaux MC, Hollande $E$ : Dissociation of Langerhans islets in the rabbit after pancreatic duct ligation. Immunocytochemical and ultrastructural studies. Virchows Arch. (Cell. Pathol.) 1987, 52, 539-551. 
Churg A, Richter WR: Early changes in the exocrine pancreas of the dog and rat after ligation of the pancreatic duct. Amer. J. Path. 1971, 63, 521-534.

Klöppel G, Dreyer T, Willemer S, Kern H, Adler $G$ : Human acute pancreatitis: its pathogenesis in the light of immunocytochemical and ultrastructural findings in acinar cells. Virchows Arch. (Pathol. Anat.) 1986, 409, 791-803.

Longnecker DS: Pathology and pathogenesis of diseases of the pancreas. Amer. J. Path. 1982, 107, 99-121.

Pang WF, Adams JH, Beasley VR, Buck WB, Haschek WM: Myocardial and pancreatic lesions induced by $\mathrm{T}-2$ toxin, a Trichothecene mycotoxin, in swine. Vet. Pathol. 1986, 23, 310-319.

Rahko T, Grönlund A-M, Kalima TV, Saloniemi $H$ : A new animal model for exocrine pancreatic insufficiency. Path. Res. Pract. 1985, 180, 309.

Rahko T, Nikander S, Kalima TV, Saloniemi H: An experimental study of exocrine pancreatic insufficiency in the pig. Proceedings 4th Joint Meeting Veterinary Pathologists, 1986, p. 136.

Rahko T, Kalima TV, Saloniemi H: Pancreatic duct obstruction in the pig: Light microscopy of chronic pancreatitis. Acta vet. scand. 1987, $28,285-289$.
Schiller WR, Syriyapa C, Anderson MC: A review of experimental pancreatitis. J. Surg. Res. 1974, 16, 69-90.

Zelander T, Ekholm R, Edlund Y: The ultrastructure of rat exocrine pancreas after experimentally occluded outflow. Ultrastruct. Res. 1964, 10, 89-102.

Zeligs J, Janoff A, Dumont AE: The course and nature of acinar cell death following pancreatic ligation in the guinea pig. Amer. J. Path. 1975, 80, 203-206.

Walters MN-I, Archer JM, Padadimitriou JM: Pancreatic duct obstruction: ultrastructural morphology of the acute phase. Pathology 1969, 1, 95-104.

\section{Sammanfattning}

Obstruktion av ductus pancreaticus hos svin. En elektronmikroskopisk undersökning av kronisk pankreatit.

Morfologiska alterationer i pankreasvävnaden beskrivs hos växande svin med ligerad pankreasgång. Fem försöksdjur, 6-7 veckor gamla, opererades och obducerades 2, 6 och 8 veckor senare. Som kontroll användes 3 sham-opererade svin. Obstruktionen förorsakade progressiv dilatation av den ligerade pankreasgången och intercellulära rupturer i epitelet. Den akinära vävnaden atrofierades och ersattes med proliferationer av immatura epitelceller utan zymogengranula.

(Received December 10, 1987).

Reprints may be requested from: Timo Rahko, Department of Pathology, College of Veterinary Medicine, PL 6, SF-00551 Helsinki, Finland. 